\title{
New polyurethane prostheses for substitution of cardiac valve disease and remodeling of the right ventricle in congenital heart malformations
}

\author{
MA Maluf \\ From 23rd World Congress of the World Society of Cardio-Thoracic Surgeons \\ Split, Croatia. 12-15 September 2013
}

\section{Background}

The biological cardiac prosthesis on the market today, are durable and functional, but still not the ideal valve replacement in children.

\section{Objectives}

Develop three different models of polyurethane prostheses prototypes for substitution in cardiac valve disease and remodeling of the right ventricle, in patients with congenital heart disease.

\section{Methods}

Based on a computed tomography angiography of the aorta, we made a delrin ring, keeping the anatomical characteristics of the aortic annulus. A matrix one following we made from stainless steel with the shape of the three cusp aortic valve, followed by preparation of the injection of liquid polyurethane segmented (SPU), using a esterolitografia technique. In vitro tests: The materials used in the manufacture of prostheses were approved in biocompatibility testing according to ISO 10993 - Biological evaluation of medical devices. The dentures will undergo physical tests, hydrodynamic and durability according to ISO 5840 - Cardiovascular Implants - Prosthetic heart valves.

\section{Results}

The macroscopic appearance of these prototypes was approved by the group of Engineer, Biologist and Pediatric Cardiac Surgeon. It will be observed the macroscopic and microscopic optical and electronic scanning and imaging studies. The data will be sorted by making emphasis on

Correspondence: miguelmaluf@gmail.com

Cardiovascular Division, São Paulo Federal University, Brazil the degree of calcification, presence of thrombi, infection and integrity of the prosthesis SPU. Experimental studies published showed good hemodynamic performance of the polyurethane prostheses, implanted on the right side of the heart: the absence of significant pressure gradients.

\section{Conclusions}

It is possible to reproduce these results and further studies, carried out to better understand the properties of the SPU and level of reliability with a view on release, compared to health authorities for clinical application, thus becoming one more option among the prostheses on the market today.

Published: 11 September 2013

doi:10.1186/1749-8090-8-S1-0141

Cite this article as: Maluf: New polyurethane prostheses for substitution of cardiac valve disease and remodeling of the right ventricle in congenital heart malformations. Journal of Cardiothoracic Surgery 2013 8(Suppl 1):0141.

Submit your next manuscript to BioMed Central and take full advantage of:

- Convenient online submission

- Thorough peer review

- No space constraints or color figure charges

- Immediate publication on acceptance

- Inclusion in PubMed, CAS, Scopus and Google Scholar

- Research which is freely available for redistribution

Submit your manuscript at www.biomedcentral.com/submit
( Biomed Central 